\title{
Iron Deficiency Anaemia: An Unusual Complication of Meckel's Diverticulum
}

\author{
Iman Al-Onaizi ${ }^{a}$ Fatma Al-Awadi a Abdul-Latif Al-Dawood ${ }^{b}$ \\ Departments of aPaediatrics and bSurgery, Al-Sabah Hospital, Kuwait
}

\section{Key Words}

Meckel's diverticulum · Haemorrhage · Iron deficiency anaemia $\cdot$ Abdominal pain

\begin{abstract}
Objectives: To describe a case of Meckel's diverticulum with an unusual complication of iron deficiency anaemia due to chronic intestinal bleeding. Clinical Presentation and Intervention: A 12-year-old boy presented with bloody diarrhoea and abdominal pain in association with a long-standing history of black stools and progressive pallor. Biochemical tests revealed low serum iron $(1.2 \mathrm{mmol} / \mathrm{l})$ indicating iron deficiency anaemia and low serum albumin $(29 \mathrm{~g} / \mathrm{l})$. The other tests were normal. Colonoscopy performed on the 8th day of hospitalization was normal. A technetium-99m pertechnetate scan showed an ectopic gastric mucosa in the Meckel's diverticulum confirmed at surgery in the region of the antimesentric border and on histopathology. Conclusion: Findings indicated that the patient had a bleeding Meckel's diverticulum, complicated by iron deficiency anaemia.
\end{abstract}

\section{Introduction}

Meckel's diverticulum occurs in about $2 \%$ of the population, making it the most prevalent congenital abnormality of the gastrointestinal tract. Nevertheless, it is mostly asymptomatic as only $4-6 \%$ of patients develop symptoms [1]. Haemorrhage is the most common complication of Meckel's diverticulum in children. Although profuse acute bright rectal bleeding is common [2, 3], chronic bleeding is uncommon. We present a case of Meckel's diverticulum with iron deficiency anaemia due to chronic intestinal bleeding.

\section{Case Report}

A 12-year-old boy was admitted to the hospital with a 1-week history of diarrhoea associated with streaks of fresh blood and suprapubic abdominal pain. His past history disclosed the presence of recurrent abdominal pain of 1-year duration as well as passage of loose black stools (melaena). During the 2 months preceding his admission, he had complained of increased fatigue and was noted to be progressively pale. His diet was adequate and there was no history of recurring fever, weight loss, skin rash, mouth ulcers or joint complaints.

Initial examination showed a pale boy with no symptoms of toxicity. His weight and height were $34 \mathrm{~kg}$ (10th-25th percentile) and $152 \mathrm{~cm}$ (just above 50th percentile), respectively. He was afebrile with a heart rate of $102 / \mathrm{min}$ and blood pressure of 100/70 $\mathrm{mm} \mathrm{Hg}$. He had no clubbing or skin rash. Chest, heart and abdominal examinations were normal. Rectal examination did not reveal any polyp or fissure.

\section{KARGER \\ Fax +4161306 1234 \\ E-Mail karger@karger.ch \\ www.karger.com \\ (c) 2002 S. Karger AG, Basel \\ 1011-7571/02/0114-0214\$18.50/0 \\ Accessible online at: \\ www. karger.com/mpp}

Al-Awadi Fatma

PO Box 25263

13113 Safat (Kuwait)

Tel. +965988 8020 or +965 4812634, Fax +965 4832154

E-Maildr_falawadi@hotmail.com 
Investigations revealed a $\mathrm{Hb}$ of $67 \mathrm{~g} / \mathrm{l}$, Hct $57 \mathrm{~g} / \mathrm{dl}, \mathrm{MCV} 73.6 \mathrm{fl}$, $\mathrm{MCH} 23.7 \mathrm{pg}$ and MCHC $32 \mathrm{~g} / \mathrm{dl}$. WBCs were $3.5 \times 10^{9} / 1$, platelets $255 \times 10^{9} / 1$ and ESR $2 \mathrm{~mm}$. Serum iron was $1.2 \mu \mathrm{mol} / 1$ (reference range 6-27), transferrin $2.7 \mathrm{~g} / 1$ (reference range 2.1-3.6) and saturation $2 \%$ (reference range 20-40). Prothrombin time was 12.9 s (control $10.5 \mathrm{~s}$ ), and partial thromboplastin time was $24.5 \mathrm{~s}$ (control $23.5 \mathrm{~s})$. His serum albumin was low $(29 \mathrm{~g} / \mathrm{l})$. All other tests were normal: total bilirubin $3 \mu \mathrm{mol} / \mathrm{l}$, alkaline phosphatase $263 \mathrm{U} / \mathrm{l}$, alanine transferrin $23 \mathrm{U} / 1$, adjusted serum calcium $2.47 \mathrm{mmol} / \mathrm{l}$, phosphorus $1.3 \mathrm{mmol} / \mathrm{l}$, creatinine $46 \mathrm{mmol} / \mathrm{l}$, urea $3.8 \mathrm{mmol} / 1$, blood glucose $5.4 \mathrm{mmol} / \mathrm{l}$, serum sodium $140 \mathrm{mmol} / \mathrm{l}$ and serum potassium $4.5 \mathrm{mmol} / \mathrm{l}$. Stool analysis revealed elevated RBCs. No ova or parasites were seen and stool culture showed no growth.

While in the hospital, he passed moderate amounts of fresh blood in stools on 2 occasions, and his $\mathrm{Hb}$ dropped to $50 \mathrm{~g} / \mathrm{l}$ (normal range $120-140 \mathrm{~g} / \mathrm{l})$. He continued to have minimal rectal bleeding and required three blood transfusions.

Colonoscopy performed on the 8th day of hospitalization was normal. Meckel's diverticulum scan performed with technetium$99 \mathrm{~m}\left({ }^{99 \mathrm{~m} T c}\right)$ pertechnetate showed a focal area of radioactive tracer accumulation in the lower abdomen just above the urinary bladder, which did not move during the study time $(1.5 \mathrm{~h})$. The above findings were suggestive of ectopic gastric mucosa (fig. 1).

Subsequently, laparoscopy was performed by introducing a laparoscope in through a 5-mm port. The Meckel's diverticulum was clearly identified at the usual site of ileum. It was a pouch of $2 \mathrm{~cm}$ in base and $3 \mathrm{~cm}$ in height at the antimesentric border (fig. 2). No other abdominal lesion was identified. The diverticulum was removed by wedge resection. The histopathology confirmed Meckel's diverticulum with gastric mucosa (fig. 3). There was no evidence of Helicobacter pylori. The patient had an uneventful recovery and has since maintained normal albumin and haemoglobin levels without the need for iron therapy.

\section{Discussion}

The clinical presentation of Meckel's diverticulum is usually caused by a complication such as rectal bleeding, intestinal obstruction, intussusception, acute inflammation or perforation. Chronic bleeding from Meckel's diverticulum is uncommon. Few cases have been reported in adults [4, 5] and 1 case in children [6], the latter in association with partial intestinal obstruction. There are various explanations for the bleeding of Meckel's diverticulum. First it may contain ectopic gastric mucosa with acid production and subsequent ulceration of the adjacent ileum. Furthermore, recurrent intussusception may cause trauma, inflammation, mucosal erosion and bleeding. Finally, an inverted Meckel's diverticulum with repeated intraluminal mechanical trauma can lead to mucosal irritation and chronic blood loss. The pathogenic role of $H$. pylori in the development of gastritis in the ectopic tissue is disputable, considering the fact that these bacteria, although resistant to gastric acid, are not resistant to bile [7].

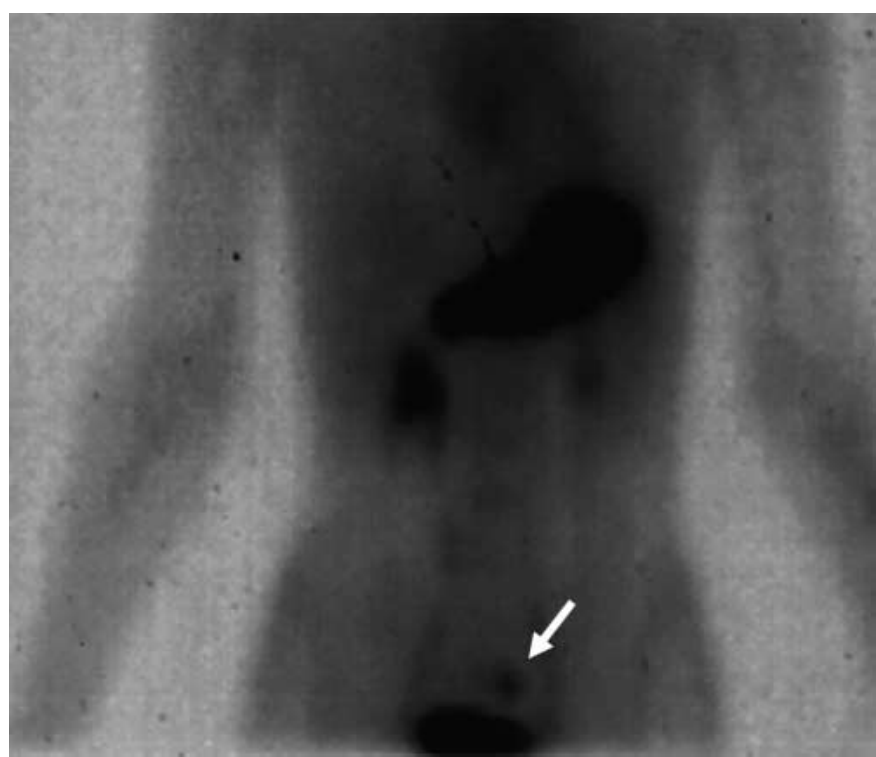

Fig. 1. Meckel's scan showing a focal area of tracer accumulation in the lower abdomen just above the urinary bladder.

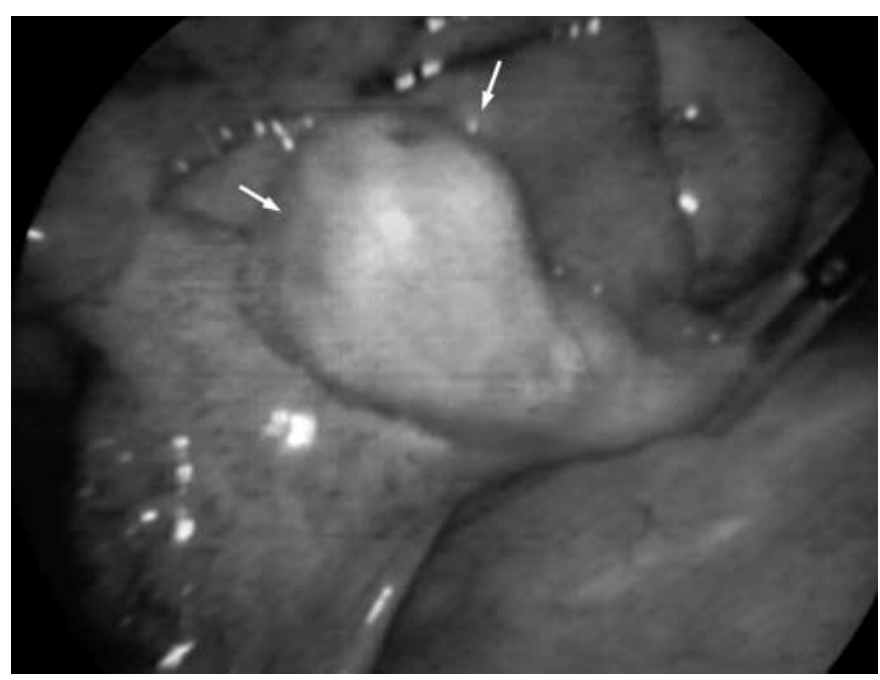

Fig. 2. Intraoperative photograph showing Meckel's diverticulum at the usual site of the ileum.

The cause of bleeding in our patient was ectopic gastric mucosa in the Meckel's diverticulum as identified by a 99m Tc pertechnetate scan (fig. 1) and confirmed by surgery and on pathology (fig. 3). Other complications such as an associated intussusception or obstruction that could have contributed to the bleeding were excluded surgically. Additionally, there was no evidence of $H$. pylori. The 
Fig. 3. Histopathological slide showing the ectopic gastric mucosa in Meckel's diverticulum.

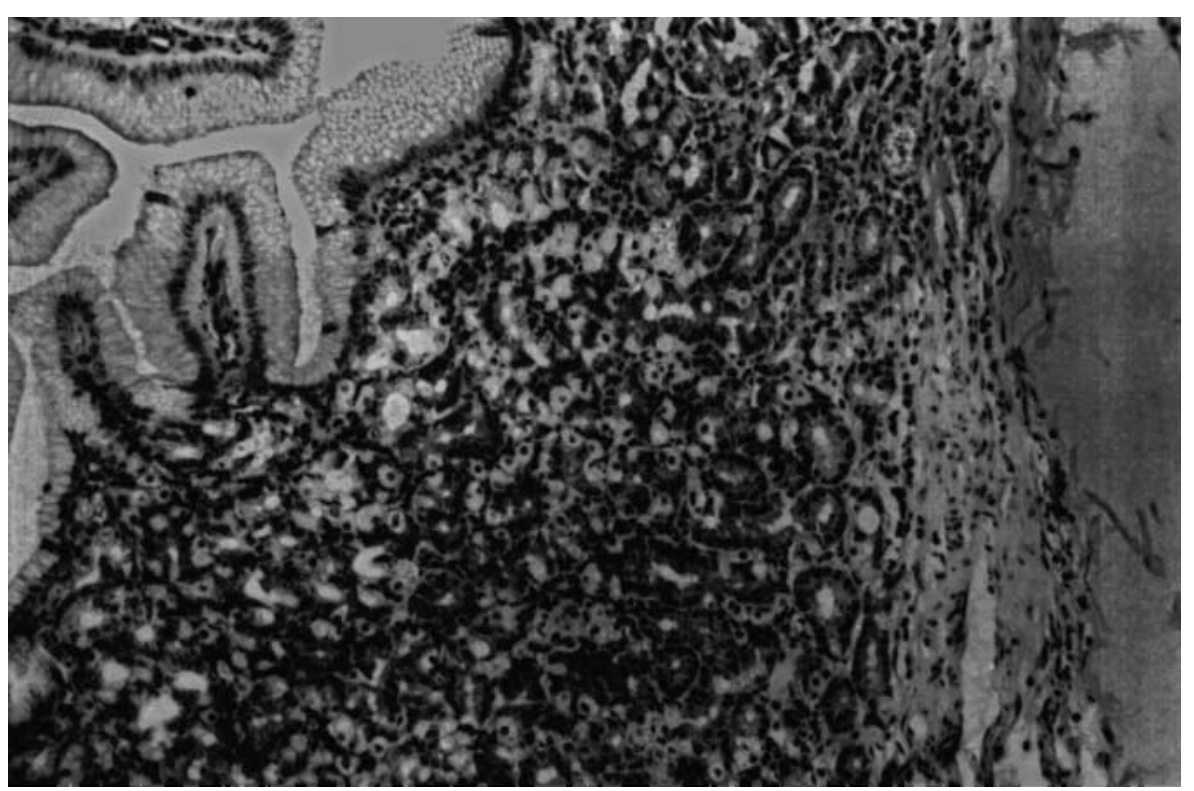

intestinal bleeding in our patient was chronic and recurrent as evidenced by the long-standing history of recurrent dark stools (melaena) and the presence of iron deficiency anaemia on admission. Had the bleeding been only an acute event, the anaemia would have been one of acute blood loss with normal red cell indices and not hypochromic microcytic with low serum iron. He had a history of good appetite, and his diet was verified to be adequate and balanced and therefore the possibility of an iron-deficient diet, as a cause of his anaemia, can be reasonably excluded.

An interesting point is that though bleeding in Meckel's diverticulum is said to be painless, it can be associated with abdominal pain in children. Such was the case with our patient, whose pain was caused by diverticulitis due to the ectopic gastric mucosa. It is worth mentioning that the pain in Meckel's diverticulum could be due to other causes such as obstruction, volvulus, intussusception and perforation [3, 8]. Initially, the presence of recurrent abdominal pain, hypoalbuminaemia and iron deficiency anaemia suggested the possibility of an inflammatory bowel disease. However, the patient showed no evidence of toxicity and had normal growth. The normal colonoscopy ruled out inflammatory bowel disease of the large bowel. Meckel's diverticulum is thought to occur much more often in association with Crohn's disease [9]. Endoscopy was not performed on our patient so we could not exclude Crohn's disease involving the small bowel. However, after surgical removal of the diverticulum and on further follow-up, the abdominal pain, anaemia and hypoalbuminaemia resolved, making it unlikely that Crohn's disease was the aetiological factor for these symptoms.

Iron deficiency anaemia is not the only anaemia associated with Meckel's diverticulum. Megaloblastic anaemia caused by bacterial overgrowth and vitamin $B_{12}$ deficiency as a result of dilatation and stasis in the adjacent obstructed ileal loop has also been reported [10]. Although chronic anaemia is an uncommon complication of Meckel's diverticulum, it could still be a prominent presentation. We urge increased awareness and strongly suggest that Meckel's diverticulum should be considered in the differential diagnosis of iron deficiency anaemia with or without obvious gastrointestinal bleeding if other more common causes have been ruled out.

In cases of diagnosed non-operated Meckel's diverticulum, we advise parents to be on the watch for any changes in stool colour. Caregivers need to do rectal examination and stool should be examined for gross and occult blood during follow-up for the possibility of chronic blood loss, which can occur at any time.

\section{Conclusion}

Our findings indicated that the patient had a chronic bleeding Meckel's diverticulum complicated by iron deficiency anemia. 


\section{References}

1 Soltero MJ, Bill AH: The natural history of Meckel's diverticulum and its relation to incidental removal: A study of 202 cases of diseased Meckel's diverticulum found in King County, Washington, over a fifteen year period. Am J Surg 1976;132:168-173.

2 Weinstein EC, Cain JC, ReMine WH: Meckel's diverticulum: 55 years of clinical and surgical experience. JAMA 1962;182:251-253.

3 Fa-Si-Oen PR, Roumen RMH, Croiset van Uchelen FAAM: Complications and management of Meckel's diverticulum: A review. Eur J Surg 1999;165:674-678.
4 Thomas WEG, Williamson RCN: Occult bleeding from Meckel's diverticulum. Br J Surg 1981;68:521.

5 Heider R, Warshauer DM, Behrns KE: Inverted Meckel's diverticulm as a source of chronic gastrointestinal blood loss. Surgery 2000;128:107-108.

6 Camps JI, Ortiz VN, Bufo A, Lobe TE: Unusual case of Meckel's diverticulum: A case report and review of an atypical form of presentation. Bol Asoc Med P R 1998;90:37-39.

7 Fich A, Talley NJ, Shorter RG, Phillips SF: Does Helicobacter pylori colonize the gastric mucosa of Meckel's diverticulum? Mayo Clin Proc 1990;65:187-191.
8 St-Vil D, Brandt ML, Panic S, Bensoussan AL, Blanchard H: Meckel's diverticulum in children: A 20 year review. J Pediatr Surg 1991;26: 1289-1292.

9 Andreyev HJN, Owen RA, Thompson I, Forbes A: Association between Meckel's diverticulum and Crohn's disease: A retrospective review. Gut 1994;35:788-790.

10 Woollner A, Shiloni E, Okon E, Freund U: Meckel's diverticulum complicated by megaloblastic anemia. Am J Gastroenterol 1982;77: 300-302. 